RELACult - Revista Latino-Americana de Estudos em Cultura e Sociedade e-ISSN 2016/Atual: 2525-7870 | e-ISSN 2015/2016: 2447-018X

\title{
Os caminhos da Ação Política: o pensamento de Arendt e Butler, a partir de dois "recortes" da atualidade
}

\author{
Los caminos de la acción política: el pensamiento de Arendt y Butler, \\ desde dos "fragmentos" de la actualidad \\ The paths of Political Action: the thought of Arendt and Butler, from two \\ "snippet" of current events
}

\author{
Bel. Eduardo Jose Bordignon Benedetti ${ }^{1}$ \\ Dra. Sônia Maria Schio ${ }^{2}$
}

\begin{abstract}
Resumo
O texto parte de acontecimentos políticos da atualidade para, na esfera do pensamento político, refletir brevemente acerca dos rumos da ação política. Para tanto, o referencial teórico de Hannah Arendt (1906-1975) é utilizado em diálogo com as obras de Judith Butler (1956-), especialmente no livro Who sings the Nation State? (2007)
\end{abstract}

Palavras-Chave: Ação; Política; Imigrantes; Arendt.

\section{Resumen}

El texto parte de los acontecimientos políticos de actualidad para, en el ámbito del pensamiento político, reflejar brevemente acerca del curso de la acción política. Por lo tanto, se utiliza del marco teórico de Hannah Arendt (1906-1975), en diálogo con la obra de Judith Butler (1956), especialmente en el libro ¿Who sings the Nation State? (2007).

Palabras claves: Acción; Política; Inmigrantes; Arendt.

\begin{abstract}
From the starting point of current political events, the text aims to reflect, in the sphere of political thought, about the course of political action. Therefore, the essay analyses the theoretical perspective of Hannah Arendt (1906-1975) and Judith Butler (1956-), especially in the book Who sings the Nation State? (2007).
\end{abstract}

Keywords: Action; Politics; Immigrants; Arendt

\section{Introdução}

Ao agirem politicamente, homens e mulheres transforam o mundo. Todavia, ao se referir a grupos como apátridas, refugiados(as), asilados(as), imigrantes ilegais (apesar de

\footnotetext{
${ }^{1}$ Bacharel em Direito, mestrando em Filosofia; Universidade Federal de Pelotas - UFPel; Pelotas, Rio Grande do Sul, Brasil eduardoj.benedetti@gmail.com.

${ }^{2}$ Doutora em Filosofia; Universidade Federal de Pelotas - UFPel; Pelotas, Rio Grande do Sul, Brasil soniaschio@hotmail.com.
} 
cada um desses grupos denotar uma situação juridicamente), percebe-se que a pertença a um Estado ainda é a condição para que a ação política ocorra sob a proteção das garantias do ordenamento jurídico. Considerando que "todas as mágoas são suportáveis se as colocarmos em uma estória sobre elas" ${ }^{3}$ o texto parte de dois "recortes" de acontecimentos políticos da atualidade (2) para retornar às categorias do pensamento político de Hannah Arendt (19061975) (3.1). Assim, objetiva-se analisar as possíveis reconfigurações necessárias aos princípios do Estado de Direito. A vitalidade do pensamento arendtiano é também investigada em diálogo com o pensamento político de Judith Butler (1956-), com espacial atenção para as considerações acerca do caráter performativo da ação $(3.2,3.3)$. Enfim, trata-se, em alusão às palavras da própria Arendt, de "compreender o que estamos fazendo" no exercício da cidadania.

\section{Dois "recortes" acerca das imigrações}

Ao tratar acerca da faculdade do pensamento, Arendt afirma que ele "emerge dos incidentes da experiência viva e a eles deve permanecer ligado, pois são os únicos pontos de apoio para se obter orientação" (1997, p. 41), sendo também necessário atentar para os "elementos subterrâneos" que se materializam em determinado acontecimento. Assim, as diversas temáticas relativas à concretização dos Direitos Humanos, para além dos estudos jurídicos e sociológicos, devem ser problematizadas no pensamento político-filosófico. Nesse sentido, apresentam-se dois "recortes", acontecimentos políticos que, em suas especificidades, exemplificam a discriminação e a resistência de imigrantes e estrangeiros, como ponto de partida para uma análise filosófica.

Recorte 1: Em 2006, foi proposto no Congresso Americano uma série de leis relativas à imigração, propondo, entre outras medidas, que o Governo Federal fosse responsável pela custódia dos imigrantes ilegais detidos, além de obrigar que os empregadores utilizassem um processo de fiscalização eletrônica para certificar-se acerca da situação legal dos seus empregados. Essas proposições levaram a uma série de protestos pelo país. Em 01 de Maio de 2006, foi organizado um boicote nacional, o Dia sem Imigrantes" ( $E l$ Gran Paro Estadounidense). Nesse contexto, o produtor britânico Adam Kidron criou, em estilo de rap, uma versão em espanhol do hino nacional dos Estados Unidos, que foi intitulada Nuestro Himno. Essa versão foi incorporada e entoada diversas vezes durante os protestos e

\footnotetext{
${ }^{3}$ A frase é da escritora dinamarquesa Isak Dinesen, citada por Arendt no início do Capítulo V da obra "A condição humana" (2010, p.217).
} 

e-ISSN 2016/Atual: 2525-7870 | e-ISSN 2015/2016: 2447-018X

sua importância política é analisada por Butler e Spivak em Who sings the Nation State? (2007).

Recorte 2: O Brasil presencia, atualmente, um crescente aumento no número de imigrantes ${ }^{4}$. Segundo dados da Polícia Federal, o número de imigrantes registrados aumentou 160\% (cento e sessenta por cento) em dez anos. Todavia, em matéria de legislação protetiva, houve poucos avanços. O Estatuto do Estrangeiro (Lei nº830/80), ainda em vigor, materializa uma perspectiva de desconfiança em relação ao Estrangeiro, tratando as migrações unicamente como questão de Segurança Nacional ${ }^{5}$.

Por exemplo, o Artigo 107 desse Estatuto, estabelece, em seu caput, que "o estrangeiro admitido no território nacional não pode exercer atividade de natureza política, nem se imiscuir, direta ou indiretamente, nos negócios públicos do Brasil”. Nesse sentido, em Abril de 2016, no contexto dos protestos acerca do impeachment da Presidenta eleita do Brasil, Dilma Roussef, a Federação Nacional dos Policiais Federais (FENAPEF) expediu uma nota $^{6}$ alertando para o risco de prisão e de deportação dos estrangeiros e imigrantes que participarem de manifestações políticas no Brasil. Conforme Nota Técnica, elaborada pelo ITTC (Instituto Terra, Trabalho e Cidadania), a nota da FENAPEF é inconstitucional, desrespeitando uma série de compromissos internacionais assumidos pelo Brasil em matéria de Direitos Humanos ${ }^{7}$.

Segundo reportou o Jornal O Estado de São Paulo " "a nota foi motivada pela suspeita sobre a vinda de bolivianos para os protestos". Em suas manifestações, os representantes da Polícia Federal, aparentemente omitiram-se acerca dos imigrantes que vivem no Brasil, posto que se referiram apenas à participação de "turistas" " nos protestos. Em oposição a essa Nota, e

\footnotetext{
${ }^{4}$ Para mais dados, consultar http://g1.globo.com/mundo/noticia/2016/06/em-10-anos-numero-de-imigrantesaumenta-160-no-brasil-diz-pf.html. Acesso em: 20.Ago.2016.

${ }^{5}$ Em 2013, foi instituída no Ministério da Justiça uma comissão para promover alterações no Estatuto do Estrangeiro. Atualmente, tramita na Câmara dos Deputados o PL 2516/2015, que institui a nova lei de migrações.

Disponível em: http://agenciabrasil.ebc.com.br/politica/noticia/2015-07/senado-aprova-lei-de-migracaoque-revelegislacao-da-epoca-da-ditadura. Acesso em: 20. Ago.2016.

6 A íntegra da Nota está disponível em: http://www.fenapef.org.br/nota-a-imprensa-estrangeiros-queparticiparem-de-atos-politicos-podem-ser-detidos-e-expulsos-do-pais/ . Acesso em: 21.Ago.2016.

${ }^{7}$ Segundo a Nota, "O ato fundamenta-se em dispositivos legais claramente contrários à Constituição Federal e aos compromissos assumidos pelo Brasil em matéria de direitos humanos, expressos, entre outros, no Pacto Internacional de Direitos Civis e Políticos e no Pacto Internacional de Direitos Econômicos, Sociais e Culturais. Mostra-se, deste modo, simultaneamente incompatível com a Constituição Federal e inconvencional".

A íntegra da nota está disponível em: http://ittc.org.br/nota-tecnica/. Acesso em: 09.Out.2016.

8 Disponível em: http://politica.estadao.com.br/noticias/geral,bolivianos-contra-o-impeachment-seraodeportados--diz-pf,10000026395 . Acesso em: 21.Ago.2016.

9 "Os direitos políticos são praticamente os últimos a serem adquiridos por estrangeiros com visto de permanência, imagine para quem vem apenas a turismo", disse o presidente da entidade, Luis Boudens" Disponível em: http://politica.estadao.com.br/noticias/geral,bolivianos-contra-o-impeachment-serao-deportados-diz-pf,10000026395. Acesso em: 21.Ago.2016.
} 

e-ISSN 2016/Atual: 2525-7870 | e-ISSN 2015/2016: 2447-018X

em alusão a previsão do Artigo $5^{\circ}$ da Constituição Federal ${ }^{10}$, foi organizado um o Ato em defesa da participação cidadã dos imigrantes, durante VII Fórum Mundial das Migrações (FSMM), que ocorreu em São Paulo de 07 a 10 de Julho de 2016.

\section{Arendt e Butler: Ação Política e Peformance}

\subsection{A Ação Política}

Arendt vivenciou e observou a realidade daqueles que são constrangidos a deixar seu Estado. A existência desses grupos atesta um paradoxo que continua presente: a cidadania entendida exclusivamente como pertença a um Estado-nação (o que exclui a figura dos apátridas e dos refugiados) ou como identificação da nacionalidade e da nação de residência (o que excluiu os imigrantes) - é que confere proteção legal aos indivíduos. Nesse ponto, o "direito a ter direitos", formulado por Arendt, trata da importância da existência de uma tutela internacional que garanta a efetividade dos Direitos Humanos. Assim, para Ela, "o direito de cada indivíduo pertencer à humanidade, deveria ser garantido pela própria humanidade" (ARENDT, 1989, p. 332). É a partir da discussão acerca dos apátridas que Butler retoma o pensamento arendtiano ${ }^{11}$, ressaltando a originalidade deste (2007, p. 14).

Arendt, em sua obra “A condição humana” (1958), ao teorizar as atividades que compõem a chamada vida ativa (o labor, o trabalho e a ação), destaca que a ação corresponde à Política ${ }^{12}$. Segundo ela (ARENDT, 2010, p. 189), "é com palavras e atos que nos inserimos no mundo humano". Por sua capacidade de agir, cada cidadão, em sua singularidade, pode dialogar publicamente, possibilitando a eclosão do novo. Conforme Arendt: "a ação jamais é possível no isolamento. Estar isolado é estar privado da capacidade de agir. A ação e o discurso necessitam da circunvizinhança de outros" (Idem, 2010, p. 201). A vedação do acesso à Política, tal como ocorreu no caso brasileiro, nega a condição humana.

Em relação aos Direitos Humanos permanece atual a constatação de Arendt em As Origens do Totalitarismo (1951): “Os Direitos do Homem, supostamente inalienáveis, mostraram-se inexeqüíveis - mesmo nos países cujas constituições se baseavam neles -

\footnotetext{
${ }^{10}$ Conforme o Artigo $5^{\text {a }}$ Constituição Federal de 1988: "todos são iguais perante a lei, sem distinção de qualquer natureza, garantindo-se aos brasileiros e aos estrangeiros residentes no País a inviolabilidade do direito à vida, à liberdade, à igualdade, à segurança e à propriedade".

${ }^{11}$ Acerca de sua relação com Arendt, Butler afirma: "Devo confessar desde o início que eu não perdi a minha relação ambivalente com Hannah Arendt, uma escritora incrível, com muitas posições políticas corajosas e interessantes. Eu sempre rejeitei a ideia, presente na obra "A Condição Humana", que estabeleceu a política como uma esfera pública, baseada na cidade-estado grega clássica, em oposição ao domínio privado, um domínio escuro a propósito, em que escravos e crianças e estrangeiros marginalizados cuidam da reprodução da vida material". (BUTLER; SPIVAK, 2007, p. 15. Tradução nossa.)

${ }^{12}$ Sobre as demais atividades da vida ativa, ver ARENDT, 2010, p. 149 e ss.
} 

e-ISSN 2016/Atual: 2525-7870 | e-ISSN 2015/2016: 2447-018X

sempre que surgiam pessoas que não eram cidadãos de algum Estado soberano" (1989, p.327). Por seu turno, Butler afirma que esse acontecimento, no contexto dos protestos contra as políticas anti-imigratórias, demonstrou a insuficiência de noções abstratas de nação e de igualdade ${ }^{13}$.

Assim, ainda ecoa a crítica de Arendt ao nacionalismo, tanto em relação à soberania como entrave a ação política genuína (no âmbito da articulação entre agentes políticos), quanto (em uma esfera macro) acerca da imposição pela força de barreiras que desmentem a "pluralidade enquanto lei da Terra". A necessidade de convivência pacífica retoma as ideias de Kant de um direito a hospitalidade universal, enquanto um direito de visitar povos e países sem ser hostilizado na condição de estrangeiro, já que "ninguém tem mais direito do que o outros a estar num determinado local da terra" (KANT, 1990, p.317). Diante disso, considerase juridicamente que o Estado deve proporcionar "a qualquer estrangeiro encontrável em seu território - mesmo que na mais fugaz das situações, na zona de transito de um aeroporto - [...] a garantia de certos direitos elementares da pessoa humana" (REZECK, 2000, p.186), como a vida, a integridade física e a prerrogativa eventual de peticionar administrativamente.

O conjunto dos protestos dos imigrantes ilegais demonstra que a ação política, conforme elaborado por Arendt, é irreversível - "não há como voltar atrás e desfazer o que foi iniciado" (SCHIO, 2012, p.167)-, imprevisível - "após o começo do evento, ele se sucede de forma que quem o engendrou perde o controle sobre seu desenrolar" (Idem) e ilimitada - "os seus limites não são distintos ou cognoscíveis, pois imersos na teia de relações" (Idem, 2012, p. 168). A ação acontece no espaço entre os homens e mulheres, não em decorrência do instinto, mas da natalidade ${ }^{14}$ - que é a condição humana de iniciar algo novo, resultando na pluralidade. Dessa forma, no centro da política, “jaz a preocupação com o mundo, não com o homem" (ARENDT, 2008, p. 158), pois é na artificialidade desse espaço comum que as obras humanas - símbolos e heranças simbólicas e materiais - são manifestadas.

\footnotetext{
${ }^{13}$ Em "As Origens do Totalitarismo" Arendt demostra que o surgimento dos povos sem estado consumou "a transformação do Estado de instrumento da lei em instrumento da nação" (ARENDT, 1989, p. 308). Ressalta-se, todavia, que o objeto de análise de Arendt deve ser situado espacialmente e temporalmente: os Estados-nação europeus, da primeira metade do século XX. Por seu turno, as análises de Spivak tratam das atuais condições globais contemporâneas, situando que a ideia de estado-nação é eminentemente europeia. Nesse sentido, Spivak (2007, p.80), reconhece que "Hannah Arendt was prescient when she talked about the fact that nation states, the connection of nation and state is just a blip in history".

${ }^{14}$ Enquanto na esfera privada, a natalidade é assinalada em todo novo nascimento - que representa o início de uma condição humana única -, na política, a natalidade é a tradução da liberdade. A natalidade torna possível rever posições passadas e mudar o habitual. Ela demonstra como a realidade não é algo dado previamente, de forma determinada. Por isso, o presente é também um contínuo "estar sendo" (Cf. SCHIO, 2012, p. 167). Assim, a vida humana é feita de "restabelecimentos e reconstituições não de começos absolutos" (ARENDT, 2000, p. $345)$.
} 
A ação é uma “cocriação contínua” (VETÖ apud SCHIO, 2012, p. 169), que não visa a algo externo ou ulterior a si mesmo. Por isso, "o sentido da ação se encontra na ação, ou melhor, o sentido da ação é a própria ação" (VETÖ apud SCHIO, 2012, p. 167). Assim, além da infindável teia de outras ações que engendrou, o fato de cantar o hino dos EUA em espanhol possui relevância política por si próprio, não sendo necessário recorrer à análises teleológicas.

\subsection{A esfera da Aparência}

O Nuestro Hino demonstra como a língua materna e a identidade cultural, questões que a princípio pertenceriam à esfera privada, possuem importância para a política; isto é, podem sair do espaço privado, tornando-se questões políticas. Nesse sentido, para Arendt, o "ser" e o "aparecer" coincidem: são indissociáveis um do outro, porque "somos do mundo, e não apenas estamos nele; somos também aparências, pela circunstância de que chegamos e partimos, aparecemos e desaparecemos [...]" (ARENDT, 2000, p.19). Nesse sentido, Arendt retoma a tradição do pensamento para questionar a falácia das teorias dos dois mundos (um sensorial, sujeito a erros e ilusões e outro extrassensorial, em que se pode alcançar verdades eternas), que tem como marco inicial o pensamento platônico ${ }^{15}$. O ser não existe além do aparecer, não há um "outro sujeito interior" que se "esconde" no transcorrer da ação; pelo contrário, é durante a ação que o sujeito identifca-se perante a si mesmo e aos demais.

A coincidência entre ser e aparência é uma decorrência do fato de "ser do mundo", porque os seres humanos "aparecem" para os outros e "percebem" aos outros simultaneamente. Por isso, a importância de garantir a todos e a todas o acesso ao espaço público. Diante disso, ressalta-se a importância, no caso dos estrangeiros que vivem no Brasil, de assegurar o direito constitucional à livre manifestação do pensamento. No pensamento de Arendt, a ação é caracterizada pela "espontaneidade", ocorre nesse lapso entre passado e futuro, em uma temporalidade que não obedece a uma cronologia linear. Em atenção a influência de Benjamin (1892-1940), a ação é "uma construção cujo lugar não é o tempo homogêneo e vazio, mas um tempo saturado de agoras" (BENJAMIN, 1994, p. 229. Grifos nossos). Essa interpretação de uma temporalidade fugidia, oferece novas perspectivas sobre o passado e concebe o futuro como promessa.

No pensamento arendtiano, o perdão e a promessa atuam frente a irreversibilidade (evanescência) e a imprevisibilidade que caracterizam a ação política. O perdão volta-se ao

\footnotetext{
${ }^{15}$ Em suas obras, Arendt empenhou-se em questionar certas dicotomias estabelecias ao longo da tradição filosófica, como entre filosofia e política, pensamento e ação, corpo e espírito, noções ambivalentes na história do pensamento (Cf. ARENDT, 1994, p.46).
} 
passado e visa a desculpar o agente pelos fatos ocorridos. A promessa, por sua vez, representa a superação das incertezas do futuro para que a ação continue a ocorrer (Cf. SCHIO, 2012, p. 168). A promessa não objetiva prever o futuro, apenas busca ordená-lo “tornando-o previsível e seguro até onde seja humanamente possível” (ARENDT, 2011, p. 82).

Ao manifestarem-se nas ruas, os imigrantes inserem sua performance pública em uma "teia" de relações, reconciliando-se com os fatos passados, buscando a superação dessa situação de exclusão social e transformando o mundo, que é um artifício humano. Essa ação, por ser Política, é também performática. A performance pública, em uma esfera de aparências, transcendente o discurso, sendo possível pensar o papel das emoções em informar e capacitar a ação individual e coletiva.

Dessa forma, percebe-se que a igualdade não é algo "dado" pela natureza, mas sim construído em um mundo comum. Nesse sentido, delineia-se a concepção arendtiana de cidadania:

A experiência histórica dos displaced people levou Hannah Arendt a concluir que a cidadania é o direito a ter direitos, pois a igualdade em dignidade e direito dos seres humanos não é um dado. É um construído da convivência coletiva, que requer o acesso a um espaço público comum. Em resumo, é esse acesso ao espaço público - o direito de pertencer a uma comunidade política - que permite a construção de um mundo comum através do processo de asserção dos Direitos Humanos (LAFER, 1997, p.58. Grifos do autor).

Em Arendt, o "direito a ter direitos" significa o direito à política. A possibilidade de que os cidadãos garantam a si mesmos o direito de falar (ou até entoar um hino) e de engendrar o inesperado é a manifestação antropológica do "direito a ter direitos" (Cf. BALIBAR, 2007, p. 730).

Nos países em que vivem, apátridas, refugiados(as), asilados(as) e imigrantes ilegais estão sob constante ameaça dos fundamentalismos e dos essencialismos identitários. No pensamento arendtiano, essas "ameaças" são reconciliadas na conjunção da pluralidade e singularidade, presentes nas ações dos próprios cidadãos. Segundo Arendt, a pluralidade diz respeito ao "fato de que os homens, e não o Homem, vivem na terra e habitam o mundo" (1989, p. 7). Assim, a pluralidade é constitutiva do próprio ser humano e comporta a singularidade: "a pluralidade é a condição da ação humana porque somos todos os mesmos, isto é, humanos, mas de tal modo que ninguém jamais é o mesmo que qualquer outro que tenha vivido, vive ou viverá. (Idem, p. 8). A condição humana da pluralidade é tida por Arendt como o fato que permite a manifestação da singularidade, por meio da fala e do 

e-ISSN 2016/Atual: 2525-7870 | e-ISSN 2015/2016: 2447-018X

pensamento. Essa singularidade é a responsável por romper com os ciclos repetitivos da natureza; ou seja, a singularidade humana implica em gerar ações que não se repetem.

\title{
3.3. A “Contradição Performativa", em Butler
}

\section{O principal argumento de Butler e Spivak em Who sings the nation state? (2007) é} de que cantar o hino em público, em outro idioma, revela uma lacuna entre a liberdade legal e a liberdade política. Acerca disso, a concepção de liberdade de Butler é desenvolvida em profícuo diálogo com Arendt:

\begin{abstract}
A liberdade não provem de mim ou de você; ela acontece em uma relação entre nós. Portanto, não se trata encontrar a dignidade humana no interior de cada pessoa, mas sim de compreender o ser humano como um ser relacional e social, cuja ação depende e articula um princípio de igualdade. Na verdade, para Arendt, não há "humano" se não houver igualdade. Nenhum ser humano pode ser "humano" sozinho. E nenhum ser humano pode ser "humano", se não agir em conjunto com os outros em condições de igualdade. Eu [Butler] gostaria de acrescentar o seguinte: A reivindicação da igualdade não só é falada ou escrita, mas surge precisamente quando os corpos aparecem juntos, ou melhor, quando, através da sua ação, eles trazem o espaço da aparência para o ser. Este espaço é um recurso e uma consequência da ação, e só funciona, de acordo com Arendt, quando as relações de igualdade são preservadas (BUTLER, 2015, p.89. Tradução nossa. Grifos nossos).
\end{abstract}

A noção de "contradição performativa", em Butler, é desenvolvida a partir da concepção de performance de Arendt, acrescendo a valorização do corpo (que, segundo ela, não pode ser concebido de maneira cindida, entre o corpo que aparece publicamente e o que realiza o trabalho e a manutenção da vida biológica) ${ }^{16}$.

Nesse sentido, a rua é um local da liberdade, do encontro de corpos; noção entendida juridicamente como "liberdade de associação", a qual é factualmente restrita para os imigrantes. Segundo elas, a contradição não denota um impasse, mas uma nova forma de insurgência (BUTLER; SPIVAK, 2007, p. 63). Assim, também a música

pode ser entendida não apenas como a expressão da liberdade ou como um anseio de emancipação - embora ela seja, claramente, ambas as coisas - mas também a rua como o local da performance pública, realizando a liberdade de reunião precisamente quando e onde é expressamente proibida por lei (Idem).

\footnotetext{
${ }^{16}$ Na obra Notes Toward A Performative Theory of Assembly (especialmente no Capítulo intitulado Bodies in Alliance and the Politics of the Street), Butler destaca que a noção de performance, na perspectiva política de Arendt, não atenta para as "maneiras pelas quais a arquitetura e as topografias do poder", estabelecidas sobre os indivíduos, influenciam na ação. Assim, segundo Butler, é também necessário pensar como o espaço age sobre os indivíduos. Ademais, ela é contrária a estabelecer uma "cisão" entre o corpo que aparece publicamente e o que é "sequestrado" para o âmbito privado (o corpo sexual, o corpo que trabalha e o corpo feminino). Para mais detalhes, ver BUTLER, 2015, p.85 e ss.
} 
Nesse ponto, Butler sugere uma interpretação da noção arendtiana do "direito a ter direitos" como uma espécie de contradição performativa, posto que esse direito é justificado por si mesmo, sem motivos anteriores. Conforme ela (BUTLER, 2009, p.vi. Tradução nossa.), essa formulação é "em si um tipo de exercício performativo; ela [Arendt] estabelece através de sua escrita o direito a ter direitos, e não há fundamento para essa reinvindicação para além dela mesma."

Ao entoarem o hino em espanhol, os(as) imigrantes ilegais efetivam um direito que é, de fato, negado a eles(as) - ou, no mínimo, constrangidos a não o exercerem, em virtude da possibilidade de deportação. Diante disso, afirmar "eu sou igual”, em um sentido de igualdade de direitos e deveres perante a lei, quando materialmente isso não ocorre, é o que Butler chama de "contradição performativa", sem a qual a mudança não é possível (BUTLER; SPIVAK, 2007, p. 66).

O conceito de contradição performativa refere-se ao momento em que a reinvindicação de direitos é incipiente, sendo que os imigrantes já a exercitam, apesar de tais direitos não possuírem eficácia material e formal. Nesse sentido, não basta reivindicar igualdade, é preciso agir nesses termos. Segundo Butler: "ser um ator político é uma função, uma característica de agir em condições de igualdade com outros seres humanos. A igualdade é uma condição e caraterística própria da ação política, ao mesmo tempo em que é seu objetivo" (BUTLER,2009, p.vii).

\section{Conclusões}

A lacuna existente entre a realidade da igualdade e o seu enunciado, torna a afirmação ("eu sou igual") radical porque demonstra que as contradições "devem ser invocadas e expostas para mover-se para algo novo" (BUTLER; SPIVAK, 2007, p. 67). Tanto as manifestações ocorridas nos EUA, quanto a proibição da participação de estrangeiros nos recentes protestos no Brasil, demonstram que a busca da liberdade é um processo contínuo, que inicia pelo seu exercício, apesar da lacuna existente entre esse exercício e o reconhecimento legal. Segundo Arendt, "ser livre e agir são uma mesma coisa" (ARENDT, 1997, p. 199); isto é, ser livre é fundar, estabelecer novos espaços humanos, é inventar a condição da liberdade. Dessa forma, a ação política é portadora da esperança quando pensa "o impensável" para determinada época.

Sendo assim, a noção de "contradição performativa", materializada na performance pública, demonstra como ainda são incipientes as políticas sociais e econômicas para os 

e-ISSN 2016/Atual: 2525-7870 | e-ISSN 2015/2016: 2447-018X

migrantes. Os protestos nos EUA, ou mesmo os entraves à participação política dos estrangeiros que vivem no Brasil, demonstram os desafios para a consolidação de princípios migratórios fundados no reconhecimento de Direitos Humanos universais ${ }^{17}$.

Por fim, conclui-se que o pensamento de Arendt permanece atual, independente e original; sendo, a sua recuperação por Judith Butler, uma prova dessa fecundidade. Por um lado, se Arendt compreende a realidade tal como se apresenta, de maneira complexa e fragmentada, ela também enfatiza a necessidade de mudança a fim de estabelecer uma comunidade plural. Essa comunidade, sob esteira do amor mundi, ${ }^{18}$ possibilita uma cidadania global a todos e todas - entendo a Terra como um espaço singularmente plural - e, a partir dessas especificidades, afirmando a universalidade do "direito a ter direitos".

\section{Referências bibliográficas}

ALMEIDA, Paulo Sérgio de. Migração e tráfico de pessoas. Cadernos de Debate Refúgio, Migrações e Cidadania, Brasília, DF, v. 7, n. 7, p. 43-50, 2012.

ARENDT, Hannah. Origens do Totalitarismo. São Paulo: Companhia das Letras, 1989.

. Lições sobre a Filosofia Política de Kant. Rio de Janeiro: Relume Dumará, 1994.

Entre o Passado e o Futuro. $4^{\mathrm{a}}$ ed., São Paulo: Perspectiva, 1997.

2002.

A Vida do Espírito: o pensar, o querer, o julgar. Rio de Janeiro: Relume Dumará, . A promessa da Política. Rio de Janeiro: Difel, 2008.

. A condição humana. Rio de Janeiro: Forense Universitária, 2010.

. Sobre a Revolução. São Paulo: Companhia das Letras, 2011.

BALIBAR, Etienne. (De)Constructing the Human as Human Institution: A Reflection on the Coherence of Hannah Arendt's Practical Philosophy. Social Research. Nova York, v.74, n.3, p. 727-738, 2007.

BENEDETTI, Eduardo Jose Bordignon. 'Direito a ter Direitos': a (re)fundação dos Direitos Humanos no pensamento de Hannah Arendt. In: Sobre Responsabilidade: Anais do III Congresso Mundial de Filosofia Moral e Política. Pelotas: NEPFil online, 2014. v. 1. p. 121132.

\footnotetext{
17 Almeida (2012, p.45 .cita como exemplos: “o direito inalienável de todo ser humano à migração e o reconhecimento de que as pessoas, independentemente de sua situação migratória, são sujeitos de direitos e devem ter integralmente respeitados seus direitos fundamentais"

${ }^{18} \mathrm{O}$ Amor Mundi é a capacidade humana de se associar aos outros através do discurso e da partilha do mundo. A amizade é ação para pensar, julgar e agir.
} 

e-ISSN 2016/Atual: 2525-7870 | e-ISSN 2015/2016: 2447-018X

BENJAMIN, Walter. Sobre o conceito de história. In: Obras escolhidas I. Magia e técnica, arte e política. São Paulo: Brasiliense, 1994.

BUTLER, Judith. SPIVAK, Gayatri. Who Sings the Nation State?. Calcutá: Seagull Books, 2007.

; Performativity, Precarity and Sexual Politics. AIBR. Revista de Antropología Iberoamericana. v.4, n. 3, p. i - xiii. IV, 2009.

; Notes Toward A Performative Theory of Assembly. Harvard University Press.

2015.

KANT, Immanuel. A Paz Perpétua e outros Opúsculos, Lisboa: Edições 70, 1990.

LAFER, Celso. A reconstrução dos direitos humanos: a contribuição de Hannah Arendt. Estudos Avançados. São Paulo, vol. 11, n. 30, p.55-65, 1997.

SCHIO, Sônia Maria. Hannah Arendt: história e liberdade: da ação a reflexão. Porto Alegre: Clarinete, 2012.

REZEK, José Francisco. Direito internacional público: curso elementar. São Paulo: Saraiva, 2000 . 